\title{
Noninvasive ventilation in acute respiratory failure
}

This article was published in the following Dove Press journal:

International Journal of COPD

II August 2014

Number of times this article has been viewed

\author{
Arantxa Mas \\ Josep Masip \\ Critical Care Department, Consorci \\ Sanitari Integral (CSI), Hospital \\ Sant Joan Despí Moisès Broggi and \\ Hospital General de l'Hospitalet, \\ University of Barcelona, Barcelona, \\ Spain
}

\begin{abstract}
After the institution of positive-pressure ventilation, the use of noninvasive ventilation (NIV) through an interface substantially increased. The first technique was continuous positive airway pressure; but, after the introduction of pressure support ventilation at the end of the 20th century, this became the main modality. Both techniques, and some others that have been recently introduced and which integrate some technological innovations, have extensively demonstrated a faster improvement of acute respiratory failure in different patient populations, avoiding endotracheal intubation and facilitating the release of conventional invasive mechanical ventilation. In acute settings, NIV is currently the first-line treatment for moderate-to-severe chronic obstructive pulmonary disease exacerbation as well as for acute cardiogenic pulmonary edema and should be considered in immunocompromised patients with acute respiratory insufficiency, in difficult weaning, and in the prevention of postextubation failure. Alternatively, it can also be used in the postoperative period and in cases of pneumonia and asthma or as a palliative treatment. NIV is currently used in a wide range of acute settings, such as critical care and emergency departments, hospital wards, palliative or pediatric units, and in pre-hospital care. It is also used as a home care therapy in patients with chronic pulmonary or sleep disorders. The appropriate selection of patients and the adaptation to the technique are the keys to success. This review essentially analyzes the evidence of benefits of NIV in different populations with acute respiratory failure and describes the main modalities, new devices, and some practical aspects of the use of this technique.
\end{abstract}

Keywords: noninvasive ventilation, acute respiratory failure, pressure support ventilation, CPAP, COPD, acute pulmonary edema

\section{Introduction}

Noninvasive ventilation (NIV) refers to the delivery of ventilatory support or positive pressure into the lungs without an invasive endotracheal airway, ${ }^{1,2}$ usually through a mask. This technique has been demonstrated to efficiently improve acute respiratory failure (ARF), avoiding the complications associated with endotracheal intubation (EI) and conventional invasive mechanical ventilation (IMV), especially ventilator-associated pneumonia. ${ }^{3,4}$

The main modality is noninvasive pressure support ventilation (NIPSV). Older modalities, such as continuous positive airway pressure (CPAP), as well as ones recently introduced into the market, have been successfully used in the setting of ARF. ${ }^{5,6}$ A recent survey carried out in USA showed that the use of NIV to treat acute exacerbations of chronic obstructive pulmonary disease (COPD) increased more than $400 \%$ in one decade (from $1 \%$ in 1998 to $4.5 \%$ in 2008 ) and was associated with a $42 \%$ reduction in IMV. ${ }^{7}$ NIV is now a first-line therapy in emergency departments, ${ }^{8}$ regular hospital wards, ${ }^{9}$ palliative $^{10}$ or pediatric ${ }^{11}$ care units, and even in out-of-hospital patients. ${ }^{12,13}$
Correspondence: Josep Masip

Consorci Sanitari Integral,

Av Josep Molins, 29-4I,

L'Hospitalet de Llobregat,

08906, Barcelona, Spain

Tel +34 93553 I 200 ext 8527 or ext 73I

Email jmasip@ub.edu 
We performed a search in PubMed National Library with the key words "non-invasive-ventilation." The search was limited to: "clinical trials", "reviews", "systematic reviews", and "meta-analyses". All randomized trials and meta-analyses were selected. Review articles were chosen according to their relevance, based on the author's reputation and the quality of the journal. Nonrandomized trials were also selected from these reviews, according to the relevance of the results and applying similar criteria.

This review focuses on the following: clinical settings in which NIV can be used; modes of NIV; interfaces; ventilators; humidification; when to apply NIV; predictors of failure; practical aspects; monitoring NIV; the use of sedation; when to stop NIV; and conclusions.

\section{Clinical settings in which NIV can be used (indications)}

There is strong evidence that the addition of NIV to standard care improves outcomes in patients with COPD exacerbation and in those with acute cardiogenic pulmonary edema (ACPE) ${ }^{14,15}$ however, the technique is also used to support patients with ARF from other etiologies. There are several contraindications to the use of NIV (Table 1) where common sense would normally prompt intubation and IMV. ${ }^{16,17}$

\section{COPD}

\section{Acute exacerbations}

A significant number of randomized trials have shown an improvement in gas exchange and symptoms with the use of NIPSV compared to conventional oxygen therapy (COT) in patients with COPD exacerbation. ${ }^{18-23}$ In addition, some

Table I Contraindications of noninvasive ventilation

\begin{tabular}{ll}
\hline Absolute & Relative \\
\hline Respiratory arrest & $\begin{array}{l}\text { Medically unstable (hypotensive } \\
\text { shock, uncontrolled cardiac } \\
\text { ischemia, or arrhythmia) }\end{array}$ \\
Unable to fit mask & Agitated, uncooperative \\
Uncontrolled vomiting or copious & Unable to protect airway \\
upper gastrointestinal bleeding & \\
Total upper airway obstruction & Swallowing impairment \\
Facial trauma & Excessive secretions not managed \\
Patient decline & by secretion clearance techniques \\
& Multiple (two or more) organ \\
& failure \\
& Recent upper airway or upper \\
& gastrointestinal surgery \\
& Progressive severe respiratory \\
failure \\
\end{tabular}

randomized trials and several meta-analyses or systematic reviews confirmed the superiority of NIPSV over COT, in that it reduced the EI rate, intensive care unit (ICU) or hospital length of stay, and mortality. ${ }^{24-29}$ Therefore, NIV should be considered a first-line treatment for these patients with COPD exacerbation, ${ }^{30-32}$ especially in those with moderate-to-severe decompensation ( $\mathrm{pH}<7.35$ and hypercapnia). To ensure better outcomes in terms of intubation and mortality, NIPSV should be initiated early, before severe acidosis occurs. ${ }^{14}$ This is especially true in patients treated with NIPSV in general wards, as Plant et al demonstrated in a large randomized trial. ${ }^{22}$ The benefit of NIPSV in cases less severe decompensation $(\mathrm{pH} \geq 7.35)$ has not been well established. ${ }^{23,33,34}$ Though $\mathrm{pH}$ is by far the most important determinant for deciding whether to institute NIPSV, other clinical factors, such as tachypnea, the severity of dyspnea, and the use of respiratory accessory muscles, should also be considered. ${ }^{35}$

The rate of NIPSV failure requiring IMV in decompensated COPD patients is low, but, in critical patients, may be as high as $60 \%$ (5\% to $60 \%))^{36,37}$ The short-term outcomes of these patients are uncertain. Although some authors did not find differences in mortality in patients who failed NIPSV compared to those who underwent IMV directly, ${ }^{38}$ a registry of patients with COPD exacerbation treated with NIV in USA from 1998 to $2008^{7}$ showed increased mortality among patients who failed NIPSV. Considering some of these variables, close monitoring and expertise is strongly recommended when NIPSV is started in patients with a high risk of failure.

COPD patients who survive an initial episode of exacerbation needing NIV are at high risk for recurrent admission and subsequent requirement of NIV. ${ }^{39}$ In a recent retrospective analysis of 100 COPD patients with respiratory acidosis treated with NIV, Chung et $\mathrm{al}^{40}$ described a median survival of 2.08 years, with a mean survival rate at 2 and 5 years of $52 \%$ and $26 \%$, respectively, significantly higher than in some studies from the $1990 \mathrm{~s}^{41}$ and closer to that described recently by Titlestad et al. ${ }^{42}$ The only strong predictors of 5-year mortality were age, body mass index, and domiciliary oxygen use. Surprisingly, the degree of acute physiological impairment when NIV was initiated was not described as a predictor of long-term survival. ${ }^{40}$

\section{Home mechanical ventilation}

In patients with chronic hypercapnic respiratory failure, longterm NIV can theoretically provide benefits by compensating nighttime hypoventilation, allowing respiratory muscles to rest, improving nocturnal gas exchange, and resetting 
central respiratory control in response to arterial partial carbon dioxide pressure $\left(\mathrm{PaCO}_{2}\right)$ concentration. Sleep quality improves, as daytime symptoms and patient survival often do as well; ${ }^{43,44}$ however, the long-term benefit from home NIV in chronic stable COPD patients remains uncertain, and current trials are focused on elucidating which patients may benefit from domiciliary NIV and what is the best ventilatory strategy. ${ }^{45} \mathrm{~A}$ recent meta-analysis including individual data from 245 stable hypercapnic COPD patients did not find any benefit in 3 or 12 months of nocturnal NIPSV other than a slight improvement of $\mathrm{PaCO}_{2}$ at 3 months' follow-up, which was more pronounced when NIPSV was applied with inspiratory positive airway pressure (IPAP) levels of $18 \mathrm{~cm}$ $\mathrm{H}_{2} \mathrm{O}$ or higher. ${ }^{46}$

To date, COPD patients remaining chronically hypercapnic after an acute exacerbation, with a greater alteration of nighttime ventilation and high adherence to the therapy, seem to be the best candidates for home ventilation. ${ }^{44,47}$ Regarding ventilatory modes, trials using low pressure levels in stable COPD patients failed to demonstrate improvement in $\mathrm{PaCO}_{2}$ and outcomes. ${ }^{43,48}$ Conversely, the use of high inspiratory pressures (20 to $40 \mathrm{cmH}_{2} \mathrm{O}$, known as high-pressure NIPSV) in an assisted or controlled mode (high pressures plus a respiratory rate beyond the spontaneous rate, known as highintensity NIPSV) could play a role in the future, as some trials have shown good results. ${ }^{43-50}$ The reduction in cardiac output is more pronounced in high-intensity NIPSV, ${ }^{51}$ and the clinical significance of this effect in patients with preexisting cardiovascular disease remains unknown.

\section{ACPE}

Either CPAP or NIPSV are used in ACPE. ${ }^{52}$ Since 1985, numerous studies have proved the superiority of CPAP (mostly set at $10 \mathrm{cmH}_{2} \mathrm{O}$ ) over standard oxygen therapy in patients with ACPE, improving gas exchange and symptoms and reducing the EI rate. ${ }^{53-61}$ Some trials ${ }^{62,63}$ have shown a reduction in the EI rate with NIPSV compared to standard therapy, especially in hypercapnic patients. ${ }^{64}$ No superiority of one technique over the other was shown in clinical trials designed to compare both techniques ${ }^{65-72}$ or in metaanalyses, ${ }^{15,73-77}$ although NIPSV tended to show a faster improvement in ARF in some studies.

Despite the beneficial effects of NIV in ACPE, the impact on mortality still remains unclear. Several meta-analyses conducted in the middle of the last decade ${ }^{73-75}$ showed a reduction in mortality with the use of CPAP; however, the Three Interventions in Cardiogenic Pulmonary Oedema (3CPO) trial, ${ }^{78}$ the largest clinical trial on NIV carried out to date, including more than 1,000 patients and published in 2008, did not show differences in 30-day mortality between conventional therapy and NIV, either CPAP, or NIPSV. Although a subsequent meta-analysis including the $3 \mathrm{CPO}$ trial still showed a significant reduction of mortality rate with CPAP (relative risk $=0.75[0.61-0.92]),{ }^{76}$ the conflicting results compared to the large trial makes it difficult to formulate a clear conclusion on this issue.

\section{Asthma}

Although a favorable response to NIPSV would be anticipated in acute asthma, little evidence supports this application. ${ }^{79-83}$ Recent reviews concluded that there is not enough evidence to support the use of NIPSV in acute asthma and that medical treatment alone may usually be effective. ${ }^{84,85}$ The use of NIPSV for asthmatic patients who decline intubation and for selected patients who are likely to cooperate with mask therapy has been suggested, but more data are needed to generally recommend this approach. ${ }^{86}$

\section{Community-acquired pneumonia}

The utility of NIV in patients with community-acquired pneumonia (CAP) is controversial because some data suggested that delaying EI with NIV could increase mortality; ${ }^{87}$ however, several randomized clinical trials have compared the efficacy of NIV over COT in patients with CAP, ${ }^{88-90}$ reporting a significant reduction in EI rate, shorter ICU stay, and lower mortality, mainly in patients with COPD. Therefore, a trial of NIV may be recommended in these patients.

\section{Weaning and postextubation respiratory failure}

NIV has been used in patients with persistent weaning failure (patients in whom the spontaneous breathing trial failed during three consecutive attempts) ${ }^{91}$ as adjunct to early liberation from IMV by shortening the time of IMV and the length of stay and lowering the incidence of complications (ventilator-associated pneumonia or septic shock). ${ }^{92-99}$ Early extubation and immediate application of NIV when patients meet weaning criteria can be a useful approach to increase weaning success rates and may reduce mortality in COPD patients, but it should be used with caution, as there is no strong evidence in terms of avoiding reintubation, even in the subgroup of patients with COPD. ${ }^{100}$

NIPSV can also be used after planned extubation in patients at high risk of deterioration (Table 2) as it could prevent postextubation ARF and reintubation. ${ }^{93-95,101}$ Recently, Ornico et $\mathrm{al}^{102}$ showed a reduction of reintubation 
Table 2 Risk factors for postextubation respiratory failure

Age $>65$ years.

Cardiac failure as the cause of intubation.

Acute Physiology and Chronic Health Evaluation (APACHE) II score $>12$ at the time of extubation.

Acute exacerbation of chronic obstructive pulmonary disease.

Chronic respiratory disease with ventilation $>48$ hours and hypercapnia during spontaneous breathing trial.

More than one of the following:

Failure of consecutive weaning trials.

Chronic cardiac failure.

Arterial partial carbon dioxide pressure $>45 \mathrm{mmHg}$ after extubation. Multiple comorbidities.

Weak cough or stridor after extubation.

rates when nasal NIV was applied immediately after planned extubation (in contrast to oxygen mask) in a small group of nonselected patients with more than 3 days with ARF needing IMV. The reintubation rate in the oxygen group was high (39\%), a fact that could be explained by the particular weaning protocol used in this study. More relevant was the finding that patients weaned by using NIV had a significantly lower hospital mortality compared with patients weaned by using COT. These promising results should be confirmed in larger, multicenter, randomized trials.

Regarding the role of NIV in treating established ARF during the postextubation period (generally 48-72 hours after extubation), no trial has reported benefits. ${ }^{103,104}$ One multicenter study ${ }^{104}$ even found slightly higher mortality in the NIV group, which was attributed to delayed reintubation (12 hours versus 2.5 hours). This is the main argument as to why current guidelines suggest that NIV should not be routinely used in patients who have postextubation ARF. ${ }^{105}$

\section{Other indications}

\section{Acute lung injury /acute respiratory distress syndrome}

Clinical studies and meta-analyses have shown negative results with the use of NIV or CPAP in acute lung injury (ALI)/acute respiratory distress syndrome (ARDS). ${ }^{106-108}$ The delay in EI may be associated with major complications. However, patients with initial ALI/ARDS (no multiple organ failure or hemodynamic instability) may be treated with NIV, avoiding EI in nearly $50 \%$ of cases. ${ }^{109}$

\section{Immunocompromised patients}

The use of NIV in ARF of different etiologies in immunocompromised patients (patients receiving immunosuppressive therapy for solid organ or bone marrow transplant ${ }^{110,111}$ ) is well supported in terms of significant reduction of EI and in-hospital mortality rates. The benefits of NIV compared with other ventilatory approaches in patients who have hematological malignancies is controversial, and further research is needed to clarify the role of NIV as respiratory support in ARF in hematologic patients. ${ }^{112-116}$

\section{Postoperative respiratory failure}

NIV may be used in the postoperative setting to either prevent or treat ARF. Although it is not clear whether NIV and CPAP may be useful in preventing ARF after low- and high-risk surgical procedures, ${ }^{105,117-119}$ it has been successfully used in patients with ARF, presented after abdominal or lungresection surgery and reducing EI rate. ${ }^{120,121}$

\section{Palliative NIV}

Palliative NIV can either be administered to offer a chance for survival or to alleviate the symptoms of respiratory distress in terminal patients. ${ }^{122}$ Among patients given NIV for ARF related to reversible causes, nearly one-half survived and returned home. ${ }^{122,123}$ The use of NIV in patients with dyspnea in terminal states is controversial, but it is effective in reducing dyspnea and in decreasing the dose of morphine in palliative use in patients with end-stage cancer. ${ }^{124}$ The preservation of communication between the patient and the family is considered one of the main benefits of NIV in this setting. The technique is widely used in patients with ARF and a do-notintubate order, with frequent use (between $25 \%$ and $100 \%$ of cases) reported by $50 \%$ of European physicians. ${ }^{125}$

\section{Chest trauma}

A recent meta-analysis including ten studies with patients with chest trauma found that NIV significantly improved oxygenation and reduced EI, length of ICU stay, and mortality (3\% deaths in the NIV group compared to $22.9 \%$ in the control group). In seven of the studies, NIV was used to treat ARF, while in the others it was used for ARF prevention. ${ }^{126}$

\section{Chest wall and neuromuscular disorders}

Home NIV can be used in conditions that can lead to chronic ventilatory failure such as scoliosis, kyphosis, thoracoplasty, muscular dystrophy (Duchenne muscular dystrophy, myotonic dystrophy, or poliomyelitis), and motor neuron diseases (amyotrophic lateral sclerosis). NIV may improve symptom control and quality of life in some of these patients. If bulbar function is impaired, tracheostomy ventilation may be required, but, in other cases, NIV is preferable. ${ }^{127}$ Its use in rapid progressive neurological disease is, however, controversial, as it could simply protract the dying process 
rather than extend good quality of life. ${ }^{127}$ In the acute setting, NIV should be used with caution in patients with rapidly progressive neuromuscular disease syndromes such as myasthenia gravis or Guillain-Barré syndrome, especially when bulbar muscles are involved, ${ }^{128}$ but it can be used to treat acute decompensation of chronic respiratory failure (ie, respiratory infection).

\section{During bronchoscopy}

Although successful experiences in selected centers have been reported, the feasibility and safety of diagnostic and therapeutic bronchoscopy in NIV is not well known and further studies are needed to clarify its impact on intubation rates and mortality in high-risk, critically ill patients. ${ }^{129}$

\section{Obesity hypoventilation syndrome}

NIV is considered a significant treatment option for patients with obesity hypoventilation syndrome (OHS). Some studies have suggested that treatment of OHS with NIV restores sleep quality and daytime vigilance and reduces cardiovascular morbidity, ${ }^{130}$ although it is not clear which is the best choice of equipment and ventilator settings. ${ }^{130-132}$ On the other hand, patients with OHS often present exacerbations of respiratory symptoms that, like COPD with progressive hypercapnia, require hospitalization and ventilatory support. By using NIV in a similar protocol to that in patients with severe COPD exacerbation, it is effective in reducing respiratory acidosis and improving respiratory rate. ${ }^{132,133}$

\section{Obstructive sleep apnea}

CPAP is the first-line treatment for moderate-to-severe obstructive sleep apnea (OSA) because it eliminates obstructive apneic/hypopneic events, resulting in improved daytime symptoms and possibly reducing adverse cardiovascular outcomes. ${ }^{132}$ On the other hand, it has been reported that nearly $50 \%$ of patients with chronic heart failure have sleep-disordered breathing, which consists of OSA caused by upper airway obstruction during sleep and Cheyne-Stokes respiration with central sleep apnea caused by respiratory control system instability. In these patients, the use of NIV (adaptive servoventilation) to compensate both abnormalities has been proposed. ${ }^{134}$

\section{Modes of NIV}

As previously mentioned, there are two major modes of NIV: CPAP and NIPSV, but many other modes have been used and some of them may have a relevant role in the future. An epidemiologic survey that included patients who received
NIPSV for ARF found that pressure support with or without positive end-expiratory pressure (PEEP) was used in $67 \%$ of cases and CPAP was used in $18 \%{ }^{135}$

\section{CPAP}

Although it was introduced earlier in medical practice, it is not essentially a "true" ventilation mode because it does not provide any inspiratory support. ${ }^{136}$ CPAP can be generated with a simple oxygen source through a hermetical mask with a PEEP valve or a Boussignac ${ }^{\circledR}$ (Vygon SA., Ecouen, France) mask, which hold a quantity of air in the lungs on expiration. The continuous positive intrathoracic pressure recruits collapsed alveolar units and increases functional residual capacity and lung compliance, improving oxygenation and the work of breathing. ${ }^{52}$ Control of fraction of inspired oxygen $\left(\mathrm{F}_{\mathrm{i}} \mathrm{O}_{2}\right)$ can be difficult, however, unless a mixer or a ventilator is used.

\section{NIPSV}

Unlike CPAP, this modality requires a ventilator. It is usually programmed with two levels of pressure: expiratory pressure (expiratory positive airway pressure [EPAP] or PEEP, similar to CPAP) and IPAP (Figure 1). When the patient starts the inspiratory effort, the ventilator delivers inspiratory assistance with pressure support using a decelerated flow, which keeps IPAP constant. When the patient finishes the inspiratory effort or the inspiratory flow descends below a preset percentage of its maximum value (usually $25 \%-30 \%$ ), the pressure support is discontinued and the pressure drops down to the predetermined EPAP. In the vast majority of NIV studies in the acute setting, the modality used is NIPSV, and this is, by far, the most used modality in acute exacerbations of COPD.

\section{Other modalities}

\section{Assist-control pressure ventilation}

Two levels of pressure (EPAP or PEEP and IPAP) are delivered as in NIPSV but at a preset respiratory rate. This is the modality used in high-intensity NIV.

\section{Proportional assist ventilation}

The inspiratory support is regulated by analyzing the elasticity and resistance of the patient, delivering an assisted ventilation proportional to the patient's effort. Target volume or pressure are not preset. Although this modality has demonstrated a better patient-ventilator synchrony, ${ }^{136,137}$ this advantage has not been translated into clinical outcomes. ${ }^{138-140}$

\section{High-flow nasal cannula}

Like CPAP, HFNC does not provide inspiratory support. The system delivers an oxygen-gas mixture that may meet or 


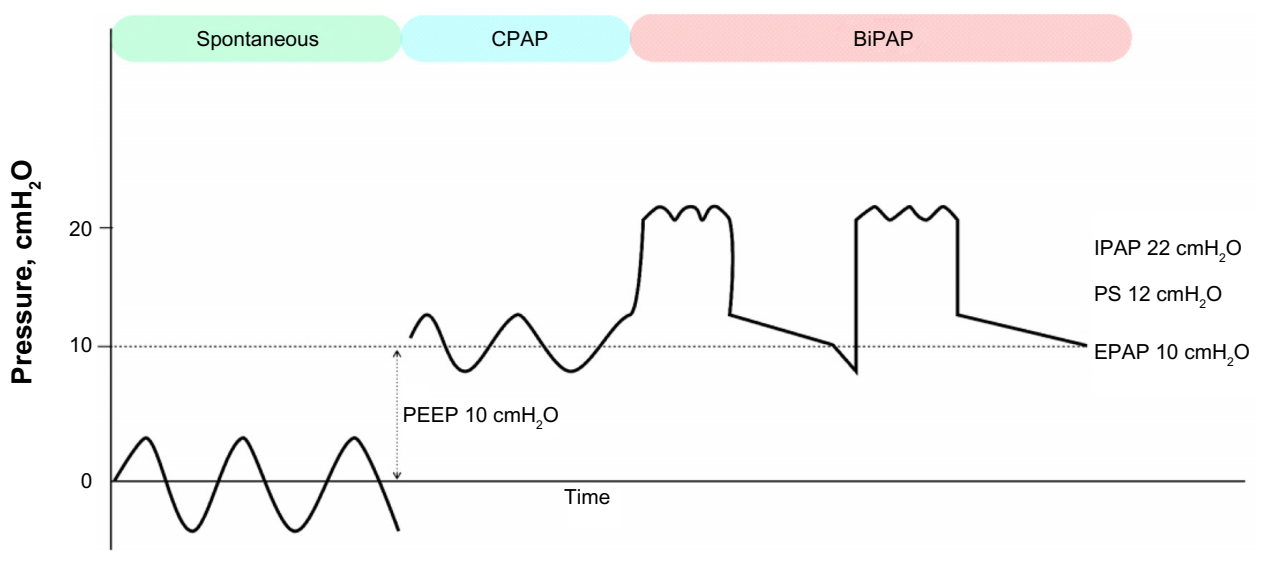

Figure I Pressure-time curves.

Note: Spontaneous breathing (CPAP: $10 \mathrm{cmH}_{2} \mathrm{O}$ ) and bilevel PS (IPAP: $22 \mathrm{cmH}_{2} \mathrm{O}$; EPAP: $10 \mathrm{cmH}_{2} \mathrm{O}$ ) with PS $12 \mathrm{cmH} \mathrm{H}_{2} \mathrm{O}$. Reproduced from Masip J, Planas K. Noninvasive ventilation. In: Tubaro M, Danchin N, Filippatos G, Goldstein P, Vranckx P, Zahger D, editors. The ESC Textbook of Intensive and Acute Cardiac Care. Oxford: Oxford University Press; 201 I:215-226.52 By permission of Oxford University Press.

Abbreviations: BiPAP, bilevel positive airway pressure; CPAP, continuous positive airway pressure; EPAP, expiratory positive airway pressure; IPAP, inspiratory positive airway pressure; PEEP, positive end-expiratory pressure; PS, pressure support.

exceed patients' spontaneous inspiratory demand, which may be up to 35 liters in adult patients with ARF. The main difference between high-flow nasal cannula (HFNC) and NIPSV is that HFNC maintains a fixed flow and generates variable pressures depending on the patient's respiratory pattern, while NIPSV provides a variable flow to generate a fixed pressure. Three action mechanisms of HFNC are postulated: first, a washout effect in nasopharyngeal dead space, simulating the benefits of tracheal gas insufflation; second, a reduction of upper airway resistance, which constitutes nearly $50 \%$ of total airway resistance; and third, a low level of positive intrathoracic pressure. ${ }^{141}$ HFNC can be effectively and safely applied in neonates with respiratory distress, children with bronchiolitis, and adults with mild-to-moderate hypoxemic respiratory failure. However, no definitive data support that HFNC is equivalent or superior to CPAP and the utility of HFNC as an alternative to CPAP requires further randomized trials.

\section{Neurally adjusted ventilatory assist}

This modality is implemented in some ventilators and is generally used to facilitate weaning in intubated patients; however, it has also been used as a form of NIV. The device uses a neural signal, the electrical diaphragm activity, to trigger and cycle off the ventilator, as well as to adapt the amount of pressure delivered. This signal occurs earlier than any flow or pressure variation, ${ }^{142,143}$ and pressure is cycled off when diaphragm activity ends. ${ }^{144}$ Neurally adjusted ventilatory assist (NAVA) improves patient-ventilation synchrony and has been shown to be superior to NIPSV by decreasing ineffective efforts and premature and delayed cyclings. ${ }^{122,144}$ The impact in relevant outcomes remains unclear, however, and the mode has important limitations: first, the system needs the insertion of an esophageal catheter; second, changes in patient position can deteriorate the signal; third, the neural drive may be affected in some diseases or with sedation; and fourth, high NAVA gains may cause an irregular respiratory pattern.

\section{Adaptive pressure control}

Adaptive pressure control, or average volume-assured pressure support, consists of an adaptive targeting scheme to adjust the inspiratory pressure to deliver at least a minimum target tidal volume. ${ }^{145}$ The ventilator provides progressively higher or lower pressure support ventilation, according to the patient's inspiratory effort and tidal volume. Depending on the ventilator, this modality has different names (AutoFlow [Evita ${ }^{\circledR}$ XL; Dräger, Lübeck, Germany]; VC+ [Puritan BennettTM 840; Covidien plc, Dublin, Ireland]; APV [GALILEO; Hamilton Medical AG, Bonaduz, Switzerland]; PRVC [Servo-i and Servo 300; Maquet, Bridgewater, NJ, USA]; and average volume-assured pressure support [BiPAP Synchrony; Philips Medical Systems, Cleveland, OH, USA]), with little differences in their algorithms. ${ }^{145,146}$ In the acute setting, adaptive pressure control has been used in adults with COPD and severe hypercapnic encephalopathy (Glasgow Coma Scale score $<10$ ), showing better clinical and gasometrical improvement than NIPSV. ${ }^{146}$

\section{Adaptive servoventilation}

Some modern home ventilators have the capability to compensate central apneas with periodic breathing by regulation of the inspiratory and expiratory pressure, treating upper airway obstruction by auto-adjustment of the end-EPAP. ${ }^{147}$ 
This modality has been successfully used to improve sleep disturbances in patients with chronic heart failure in whom central and peripheral apneas are frequent, ${ }^{148}$ and in patients with complex sleep apnea syndrome, characterized by the development of frequent central apneas or a Cheyne-Stokes respiratory pattern after initial application of CPAP. ${ }^{147}$

\section{Negative pressure ventilation}

There are few groups still using this modality, usually with a cuirass or jacket (poncho), to support patients with chest wall disorders. ${ }^{127}$

\section{Interfaces}

Whatever NIV technique is used, an interface is needed to connect the patient to a ventilator or to an air/oxygen source (Figure 2). Interfaces are devices that connect the ventilator tubing to the patient's face and facilitate the entry of pressurized gas into the upper airway. Interface-related problems are, by far, the most common reason for NIV intolerance. Patient comfort and synchrony are essential when choosing an interface, as internal volume is not related to effective dead space when NIPSV is delivered. ${ }^{149}$

\section{Nasal interface}

It has been the most commonly used interface in chronic respiratory failure $(73 \%)$, followed by nasal pillow, facial masks, and mouth pieces, ${ }^{150}$ this trend is changing with the application of new modes of home NIV, which are usually applied with a face mask ${ }^{47,51}$ Nasal masks are less useful in acute critical situations, generating more resistance ${ }^{151,152}$ and massive leakage through the mouth, often requiring mask change. ${ }^{153}$ On the other hand, they permit speech, feeding, coughing, and expectoration, reducing the risk of vomiting. ${ }^{150}$ Nasal pillows are a variant that are inserted into the nostrils; these are commonly used in pediatric patients.

\section{Face masks}

Face masks are the most common interface in clinical practice in Europe, used in over $70 \%$ of all patients requiring NIV. ${ }^{154}$ Disadvantages include lack of protection from vomiting, nasal skin injuries, nasal congestion, mouth dryness, eye irritation, speaking difficulty, and possible claustrophobia. ${ }^{153}$ There are two types of face masks.

\section{Oronasal masks}

An oronasal mask covers the mouth and nose. It increases minute ventilation and reduces $\mathrm{PaCO}_{2}$ more effectively than nasal masks in COPD patients. ${ }^{151}$ It is the most frequently used interface in Europe, ${ }^{154}$ being indicated specifically in mouth-breathing patients with dyspnea. Different sizes and models are necessary to ensure a correct adaptation to the patient.

\section{Interfaces}
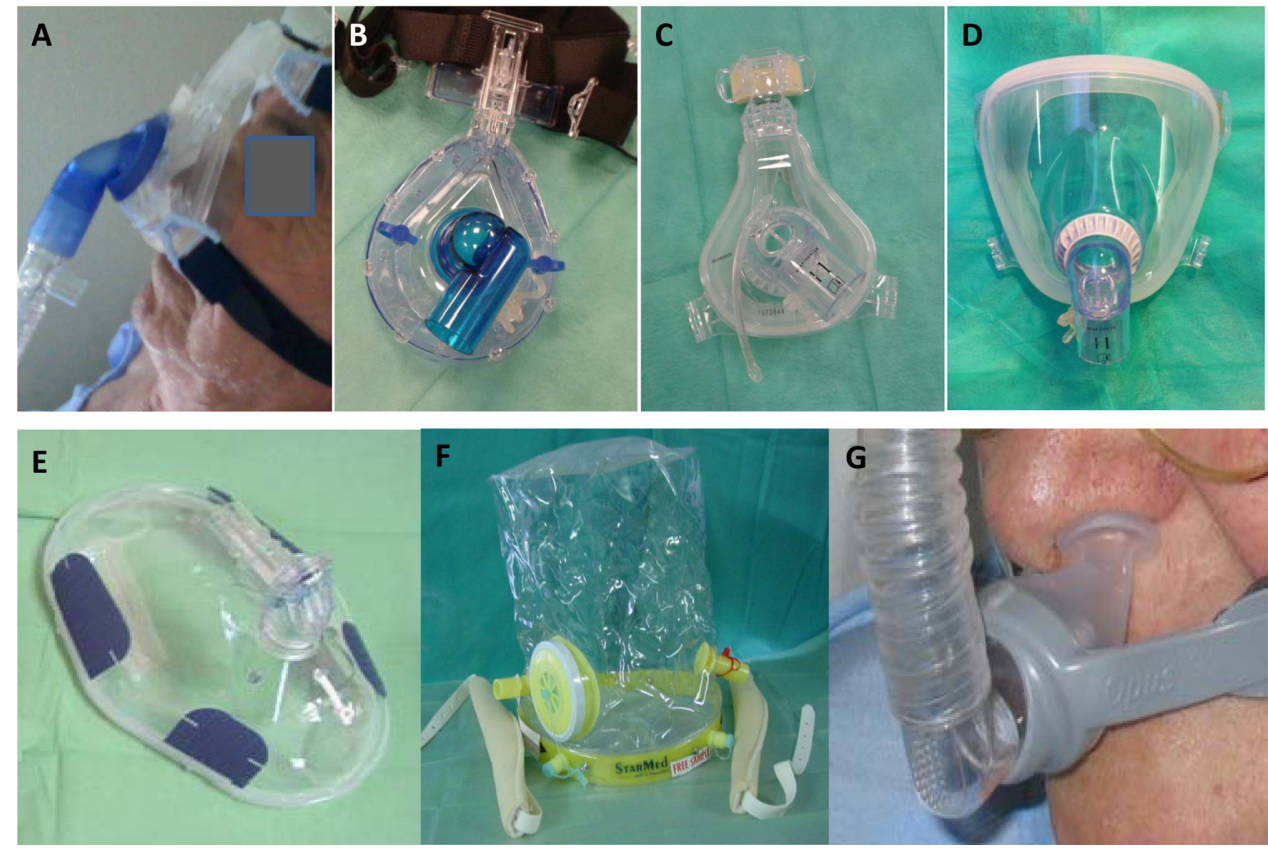

Figure 2 Interfaces for noninvasive ventilation.

Notes: (A) nasal mask; (B and $\mathbf{C}$ ) oro-nasal masks; (D and E) full-face masks; (F) helmet; (G) nasal pillows. Pictures (A) and (G) were provided by JM Carratalà from H Universitario de Alicante, Spain. 


\section{Total/full-face masks}

A total/full-face mask covers the mouth, nose, and eyes. In general, little cooperation is required to achieve a correct adaptation, with easy fitting and application, and this type of mask provokes fewer skin injuries compared to oronasal masks. ${ }^{155,156}$ They may be more comfortable than oronasal masks in longer treatments, ${ }^{157,158}$ although their superiority has not been demonstrated. ${ }^{147,159}$ As total face masks are probably the best tolerated, they may become an alternative in cases in which mask intolerance is the primary reason for failing NIV and should be available in units where NIV is routinely applied. ${ }^{157}$

\section{Helmet}

A helmet covers the whole head and part of the neck. It seems to provide some advantages over other interfaces: it is well tolerated by patients, allows acceptable interaction with the environment, and can be used in difficult anatomic situations, such as in patients who are edentulous or have facial trauma. In contrast to facial masks, helmets do not make contact with the patient's face and therefore do not cause skin lesions. ${ }^{17}$ The helmet allows more patient autonomy (speaking, reading, and eating), but the noise can be annoying. ${ }^{160}$ The use of the helmet is not recommended with traditional ventilators, as a fresh gas flow high enough to minimize rebreathing is necessary. ${ }^{160}$ It is more appropriate for CPAP because the increased dead space may generate asynchrony when NIPSV is applied. ${ }^{43,161,162}$

\section{Other}

Mouthpieces placed between lips and held in place by lip seals are less effective due to higher leakage and asynchrony rates and greater patient discomfort. ${ }^{163,164}$ Mouth pieces and nasal pillows can be applied as a rotating strategy with other interfaces.

\section{Ventilators}

There are three types of ventilators for NIPSV: portable ventilators designed specifically for NIV; transport ventilators; and ICU ventilators. Classical ICU ventilators (connected to air and oxygen gas sources) and transport ventilators (connected to an oxygen source) were primarily configured to be used with EI, and provided different levels of monitoring and security alarm systems, but often failed during NIPSV when leaks were present. Modern ICU ventilators and some transport ventilators have solved this drawback by incorporating NIV algorithms.

In contrast with ICU ventilators, NIV ventilators are more economical, easily portable, and do not need an airflow source. A wide range of portable ventilators is currently on the market, from the most simple (only pressure is modifiable) to the latest generation of high-tech ventilators (monitoring, alarm setting, leakage compensation, different triggers, cycling and flow ramp control, etc), ${ }^{165}$ which allow better synchrony than ICU and transport ventilators, including even those with adapted NIV algorithms. ${ }^{165}$

The most important attribute of the equipment is leakage compensation by means of an increase of airflow (up to 120-180 L/minute), which maintains tidal volume, producing better patient-ventilator synchrony and higher system efficacy. Since pressure cycling can increase auto-PEEP, trigger is usually activated with airflow. ${ }^{166}$

All the ventilators have particular settings for CPAP. Furthermore, CPAP can be applied without a ventilator using the Boussignac mask. The oxygen flows through smalldiameter channels in cylinder walls and is injected at high speed into the cylinder through angled side channels. The resulting turbulence, together with air friction, creates pressure on the patient's side cylinder opening, acting as a flow barrier or virtual PEEP valve. This is a very simple technique that may be used in areas with little equipment (Figure 3). ${ }^{167}$

\section{Humidification}

NIV is often applied without humidifying devices, because inspired gases are heated and humidified on the way to the alveoli; however, dry gas provokes dryness of the mouth, nose, and respiratory tract, resulting in nasal congestion and an increase of airway resistance during NIV. Up to $60 \%$ of patients with sleep apnea syndrome using nasal CPAP experience nasal congestion and dryness of the nose, mouth, and throat. ${ }^{168}$ Consensus statements and guidelines for NIV contain conflicting recommendations concerning humidification. ${ }^{169}$ When it is applied, heat humidification is recommended because it seems to facilitate NIV ${ }^{170,171}$ by reducing nasal resistance, aiding expectoration, and improving adherence and comfort, ${ }^{168}$ especially in patients with respiratory secretions. Heat and moisture exchangers are not indicated when using NIV, since they may increase circuit dead space (increased $\mathrm{PaCO}_{2}$ ) and the work of breathing. ${ }^{172,173}$

\section{Where to apply NIV}

The clinical benefits of NIV are so relevant in treating some patients with ARF that its use has been extended out of the ICU and into patient location.

Numerous experiences have been reported in studies showing the feasibility and lack of complications using CPAP 

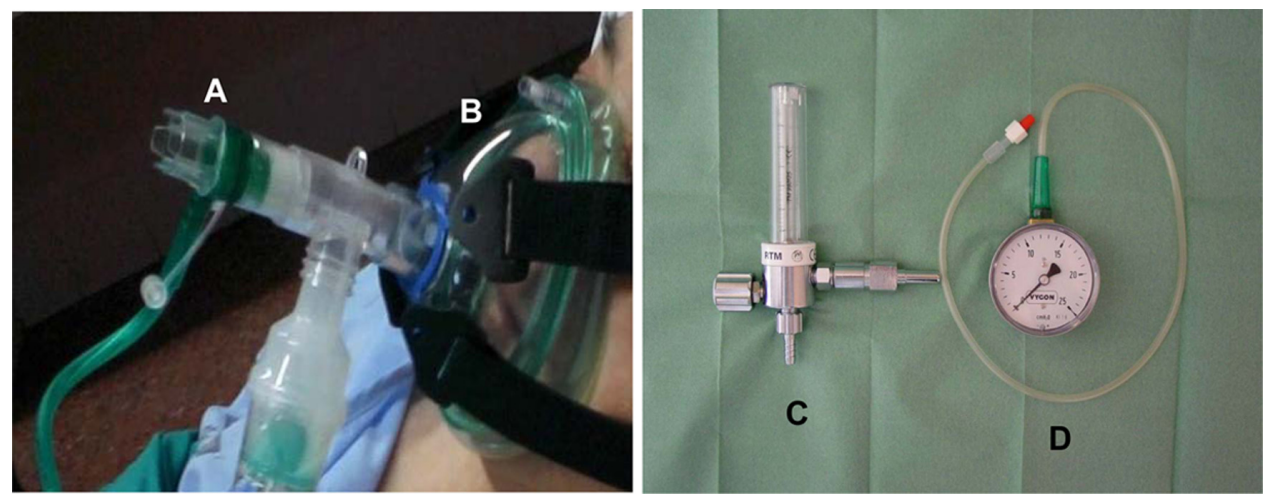

Figure 3 Equipment needed for continuous positive airway pressure Boussignac technique.

Notes: (A) Boussignac valve; (B) oro-nasal mask; nebulization device between (A) and (B); (C) 30-liter oxygen flowmeter; and (D) pressure gauge. The picture containing (A) and (B) was provided by JM Carratalà from $\mathrm{H}$ Universitario de Alicante, Spain.

to treat ACPE in out-of-hospital emergencies, ${ }^{11,174,175}$ with improvement in short-term outcomes. ${ }^{175}$

Regarding the use of NIV out of the hospital, there are insufficient data to recommend its general use. ${ }^{176,177}$ The medical or paramedical personnel-to-patient ratio is higher than that usually seen in any hospital department (including ICU), often counterbalancing the limitations of space or lower skill qualification characteristic of this setting.

NIV is routinely applied in emergency departments in the initial period of stabilization and in some specialized wards. ${ }^{22,38,178,179}$ Severely ill patients, however, need a higher nurse-to-patient ratio and level of monitoring. Although the need for EI is reduced remarkably by NIV, it is not entirely abolished, so it is definitely advisable to manage patients with more severe ARF in the ICU, where EI can be rapidly performed if necessary. ${ }^{16}$

\section{Predictors of failure and complications}

Before starting NIV, it is crucial to identify if the patient is a good candidate. There is a therapeutic window in which NIV should be used, avoiding those patients with mild ARF that would easily respond to COT or, conversely, those who present very severe ARF needing EI. ${ }^{171}$ It is necessary to consider predictors of failure (Table 3 ) that warrant closer monitoring, paying attention to possible complications like hypotension, pneumothorax, gastric insufflation, and vomiting, with the risk of aspiration pneumonia. Intubation may be preferred if the likelihood of NIV failure is very high. Subjects who have a $\mathrm{pH}<7.25$, an Acute Physiology and Chronic Health Evaluation (APACHE) II score $>29$, and a Glasgow Coma Scale score $<11$ have failure rates ranging from $64 \%$ to $82 \% .{ }^{170,171,180}$ Patients with excessive respiratory secretions or without improvement after 60 minutes of NIV may also be at high risk of failure. ${ }^{29,181-183}$ Clinical signs that are only equivocal on presentation become more definitively predictive of failure if they persist after 2 hours of NIV. ${ }^{180}$

In our experience, there are three levels that may influence NIV success: the patient (cause of ARF, patient condition, adaptation to NIV); the physician (concomitant therapy, expertise in the use of NIV, team attitude); and the device (ventilator sets, adequate interface, monitoring equipment).

\section{Practical aspects}

Clear instructions and frequent encouraging stimuli should be given to all patients at the beginning of treatment, often while fitting the mask manually.

Table 3 Predictors of failure of noninvasive ventilation therapy in acute respiratory failure

\begin{tabular}{|c|c|c|}
\hline Before starting & $\begin{array}{l}\text { After initiation } \\
\text { NIV }\end{array}$ & After 60 minutes \\
\hline $\begin{array}{l}\text { Acute respiratory } \\
\text { distress syndrome }\end{array}$ & $\begin{array}{l}\text { Excessive air } \\
\text { leakage }\end{array}$ & $\begin{array}{l}\text { No reduction in } \\
\text { respiratory rate }\end{array}$ \\
\hline $\begin{array}{l}\text { Altered mental } \\
\text { status }\end{array}$ & $\begin{array}{l}\text { Breathing } \\
\text { asynchrony with } \\
\text { the ventilator }\end{array}$ & No improvement in $\mathrm{pH}$ \\
\hline Shock & $\begin{array}{l}\text { Bad subjective } \\
\text { tolerance }\end{array}$ & $\begin{array}{l}\text { No improvement in } \\
\text { oxygenation }\end{array}$ \\
\hline $\begin{array}{l}\text { High severity } \\
\text { scores }\end{array}$ & $\begin{array}{l}\text { Neurological or } \\
\text { underlying disease } \\
\text { impairment }\end{array}$ & $\begin{array}{l}\text { No reduction in carbon } \\
\text { dioxide }\end{array}$ \\
\hline Copious secretions & & Signs of fatigue \\
\hline $\begin{array}{l}\text { Extremely high } \\
\text { respiratory rate }\end{array}$ & & \\
\hline $\begin{array}{l}\text { Severe hypoxemia } \\
\text { in spite of high } \\
\text { fraction of inspired } \\
\text { oxygen }\end{array}$ & & \\
\hline
\end{tabular}

Abbreviation: NIV, noninvasive ventilation. 


\section{Ventilator settings}

Although clinical guidelines and reviews recommend starting with low levels of pressure (IPAP: $8-10 \mathrm{cmH}_{2} \mathrm{O}$; EPAP: 3-4 $\mathrm{cmH}_{2} \mathrm{O}$ ) and increasing pressure support progressively according to patient adaptation, ensuring expired tidal volumes $>4-6 \mathrm{~mL} / \mathrm{kg}$ (it can be lower in COPD patients), there are no clinical trials that address the best way to start and continue NIPSV. In our experience, these initial parameters are well tolerated at the onset; later, with a pressure support of $12-18 \mathrm{cmH}_{2} \mathrm{O}$ above PEEP, a tidal volume of $400-500 \mathrm{~mL}$ is commonly reached. Elevated pressures may cause excessive air leakage, asynchrony (especially when the patient is tachypneic), and discomfort. On the other hand, a PEEP over $4 \mathrm{cmH}_{2} \mathrm{O}$ is necessary to avoid rebreathing when using portable ventilators, which may not include an expiratory valve or double inspiratory/expiratory circuit. ${ }^{184} \mathrm{~F}_{\mathrm{i}} \mathrm{O}_{2}$ should be titrated to achieve the desired oxygen saturation by pulse oximetry ( $>95 \%$ in general).

\section{Monitoring NIV}

Visualization of flow and pressure waveforms on the display is strongly recommended. In a recent study, physicians obtained a more rapid $\mathrm{pH}$ normalization in patients needing NIV for COPD exacerbation, with a faster $\mathrm{PaCO}_{2}$ reduction in the first 6 hours of ventilation, than just controlling numerical variables on the display, although the NIV success rate was not affected by this ventilatory approach. ${ }^{185}$

To ensure the success of NIV, close monitoring is necessary, especially of respiratory rate (patient's effort), oxygen saturation (to adjust $\mathrm{F}_{\mathrm{i}} \mathrm{O}_{2}$ ), and $\mathrm{pH}$ and $\mathrm{PaCO}_{2}$ (to assess efficacy). In addition to continuous observation, overall reassessments are usually performed at 60 and/or 90-120 minutes. One of the key factors determining tolerance to NIV (and its success) is optimal synchrony between the patient's spontaneous breathing activity and the ventilator's set parameters, known as "patient-ventilator interaction". The modality of pressure support ventilation unavoidably induces a certain degree of asynchrony, even in intubated patients. ${ }^{186}$ Asynchrony Index (AI) is calculated as follows:

$$
\begin{aligned}
(\%)= & \text { number of events } /(\text { ineffective breaths } \\
& + \text { ventilator cycles }) \times 100
\end{aligned}
$$

An $\mathrm{AI}>10 \%$ is considered severe, leading to an increase in the work of breathing and patient discomfort. ${ }^{186}$ Although several mechanisms may be responsible for asynchrony, air leakage is involved in many of them. In general, a leak of $<0.4 \mathrm{~L} /$ second $(<25 \mathrm{~L} /$ minute) is well tolerated. Asynchrony is usually manifested in different forms that each require specific approaches.

\section{Trigger asynchrony}

Trigger asynchrony is manifested in the form of ineffective efforts, double triggering, and auto-triggering. These asynchronies should be managed by tuning the trigger, adjusting the level of pressure support, and reducing the leakage.

\section{Flow asynchrony}

Flow asynchrony is manifested when rising time and flow cycle are not in accordance with patient's demand. A shorter rise time and higher flow cycle should be considered in patients with tachypnea, while slower rise time may be more comfortable in patients with low respiratory drive.

\section{Cycle asynchrony}

Short cycle (premature cycling off)

Many ventilators have cycling off set at $25 \%-30 \%$ of the peak inspiratory flow. By titrating the expiratory trigger, the duration of the cycle may be regulated. In COPD patients, it is often set at $50 \%$. ${ }^{185}$

\section{Prolonged cycle (delayed cycling off)}

A prolonged cycle is a cycle with a mechanical inspiratory time greater than the patient's inspiratory time. The reduction of air leaks and/or titration of expiratory trigger, as well as setting of maximal inspiratory time, are actions that may compensate this asynchrony.

\section{Auto-PEEP}

In auto-PEEP, the flow curve does not reach 0 at the end of expiration and titration of PEEP (at least until $85 \%$ in COPD patients) is required to compensate this.

As a general rule, measures to reduce asynchrony should be taken by changing pressure support by steps of $2 \mathrm{cmH}_{2} \mathrm{O}$, and inspiratory and expiratory triggers by steps of $5 \%$ to $10 \%$. ${ }^{185}$

\section{The use of sedation}

Although sedation can play a role in preventing intolerance to NIV, it is also potentially dangerous because of the risk of oversedation. The sedation and analgesic regimens that physicians prefer to use during NIV are quite varied. Benzodiazepines (33\%) and opiates (29\%) are reported to be the most often selected sedative agents for NIV. ${ }^{125}$ 
Morphine, remifentanil, dexmedetomidine, propofol, and midazolam-based regimens have all been used with no serious complications in experienced units. ${ }^{187,188}$ The new $\alpha 2$ adrenoreceptor agonist dexmedetomidine showed similar clinical results to midazolam in decompensated COPD with fewer adjustments in its dose, ${ }^{189}$ and it was superior to midazolam in patients with ACPE intolerant to NIV. ${ }^{187}$

\section{When to stop}

NIV is usually stopped when a satisfactory recovery has been achieved or, conversely, when there are signs of NIV failure. If NIV has been successful, the next step depends on the cause and duration of NIV. In mid- or long-term use, a weaning period is often carried out, which involves decreasing PEEP and ventilatory settings progressively. The application of a protocol-directed weaning has shown clear advantages in this context. ${ }^{190}$ This approach does not seem to be necessary in short-term use. If the patient deteriorates when NIV is interrupted, the therapy is resumed, but, otherwise, NIV may be discontinued. ${ }^{180}$

\section{Conclusion}

NIV is the first option for ventilatory support in ARF of COPD exacerbations or ACPE and should be considered in immunocompromised patients, difficult weaning, and the prevention of postextubation failure. It can also be used in the postoperative period and in cases of pneumonia and asthma or as a palliative treatment. NIV is currently used in a wide range of settings, from the ICU to home care. The appropriate selection of patients and the capacity of the team and the patients to achieve a proper adaptation to the technique are the bottom line for success. Despite no significant technological discoveries in the area of ARF in recent years, new ventilatory modes and interfaces have recently been introduced and others are under development to optimize hospital care, home ventilation, and the control of sleep disorders, further expanding the role of NIV in the health system. In conclusion, NIV should currently be considered in the treatment of the majority of patients with ARF failure.

\section{Disclosure}

The authors report no conflicts of interest in this work.

\section{References}

1. Hillberg RE, Johnson DC. Noninvasive ventilation. $N$ Engl J Med. 1997;337:1746-1752.

2. Mehta S, Hill NS. Noninvasive ventilation. Am J Resp Crit Care Med. 2001;163:540-577.
3. Girou E, Brun-BuissonC, Taillé S, Lemaire F, Brochard L. Secular trends in nosocomial infections and mortality associated with noninvasive ventilation in patients with exacerbation of COPD and pulmonary edema. JAMA. 2003;290:2985-2991.

4. Girou E, Schortgen F, Delclaux C, et al. Association of noninvasive ventilation with nosocomial infections and survival in critically ill patients. JAMA. 2000;284:2361-2367.

5. Brochard L, Isabey D, Piquet J, et al. Reversal of acute exacerbations of chronic obstructive lung disease by inspiratory assistance with a face mask. N Eng J Med. 1990;323:1523-1530.

6. Meduri GU, Conoscenti CC, Menashe P, Nair S. Noninvasive face mask ventilation in patients with acute respiratory ventilation. Chest. 1989;95:865-870.

7. Chandra D, Stamm JA, Taylor B, et al. Outcomes of noninvasive ventilation for acute exacerbations of chronic obstructive pulmonary disease in the United States, 1998-2008. Am J Respir Crit Care Med. 2012;185(2):152-159.

8. Jois-Bilowich P, Diercks D. Emergency department stabilization of heart failure. Heart Fail Clin. 2009;5:37-42.

9. Farha S, Ghamra Z, Hoisington ER, Butler RS, Stoller JK. Use of noninvasive positive-pressure ventilation on the regular hospital ward: experience and correlates of success. Respir Care. 2006;51:1237-1243.

10. Cuomo A, Delmastro M, Ceriana P, et al. Noninvasive mechanical ventilation as a palliative treatment of acute respiratory failure in patients with end-stage solid cancer. Palliat Med. 2004;18:602-610.

11. Deis JN, Abramo TJ, Crawley L. Noninvasive respiratory support. Pediatr Emerg Care. 2008;24:331-338.

12. Weitz G, Struck J, Zonak A, Balnus S, Perras B, Dodt C. Prehospital noninvasive pressure support ventilation for acute cardiogenic pulmonary edema. Eur J Emerg Med. 2007;14:276-279.

13. Plaisance P, Pirracchio R, Berton C, Vicaut E, Payen D. A randomized study of out-of-hospital continuous positive airway pressure for acute cardiogenic pulmonary oedema: physiological and clinical effects. Eur Heart J. 2007;28:2895-2901.

14. Lightowler JV, Wedzicha JA, Elliott MW, Ram FS. Noninvasive positive pressure ventilation to treat respiratory failure resulting from exacerbations of chronic obstructive pulmonary disease: Cochrane systematic review and meta-analysis. BMJ. 2003;326:185-189.

15. Masip J, Roque M, Sánchez B, Fernández R, Subirana M, Expósito J. Noninvasive ventilation in acute cardiogenic pulmonary edema. Systematic review and meta-analysis. JAMA. 2005;294: 3124-3130.

16. Nava $\mathrm{S}$, Hill N. Non-invasive ventilation in acute respiratory failure. Lancet. 2009;374:250-259.

17. Peñuelas O, Frutos-Vivar F, Esteban A. Noninvasive positive-pressure ventilation in acute respiratory failure. CMAJ. 2007;177(10):1211-1218.

18. Bott J, Carroll MP, Conway JH, et al. Randomized controlled trial of nasal ventilation in acute ventilatory failure due to chronic obstructive airways disease. Lancet. 1993;341:1555-1557.

19. Brochard L, Mancebo J, Wysocki M, et al. Noninvasive ventilation for acute exacerbations of chronic obstructive pulmonary disease. $N$ Engl J Med. 1995;333:817-822.

20. Angus RM, Ahmed AA, Fenwick LJ, Peacock AJ. Comparison of the acute effects on gas exchange of nasal ventilation and doxapram in exacerbation of chronic obstructive pulmonary disease. Thorax. 1996;51:1048-1050.

21. Celikel T, Sungur M, Ceyhan B, Karakurt S. Comparison of noninvasive positive pressure ventilation with standard medical therapy in hypercapnic acute respiratory failure. Chest. 1998;114:1636-1642.

22. Plant PK, Owen JL, Elliott MW. Early use of non-invasive ventilation for acute exacerbations of chronic obstructive pulmonary disease on general respiratory wards: a multicentre randomised controlled trial. Lancet. 2000;355:1931-1935.

23. Collaborative Research Group of Noninvasive Mechanical Ventilation for Chronic Obstructive Pulmonary Disease. Early use of non-invasive positive pressure ventilation for acute exacerbations of chronic obstructive pulmonary disease: a multicentre randomized controlled trial. Chin Med J (Engl). 2005;118:2034-2040. 
24. Keenan SP, Sinuff T, Cook DJ, Hill NS. Which patients with acute exacerbation of chronic obstructive pulmonary disease benefit from noninvasive positive-pressure ventilation? A systematic review of the literature. Ann Intern Med. 2003;138:861-870.

25. Caples S, Gay PC. Noninvasive positive pressure ventilation in the intensive care unit: a concise review. Crit Care Med. 2005;33: 2651-2658.

26. Keenan SP, Kernerman PD, Cook DJ, Martin CM, McCormack D, Sibbald WJ. Effect of noninvasive positive pressure ventilation on mortality in patients admitted with acute respiratory failure: a meta-analysis. Crit Care Med. 1997;25:1685-1692.

27. Peter JV, Moran JL, Phillips-Hughes J, Warn D. Noninvasive ventilation in acute respiratory failure: a meta-analysis update. Crit Care Med. 2002;30:555-562.

28. Ram FS, Picot J, Lightowler J, Wedzicha JA. Non-invasive positive pressure ventilation for treatment of respiratory failure due to exacerbations of chronic obstructive pulmonary disease. Cochrane Database Syst Rev. 2004;(3):CD004104.

29. Antón A, Güell R, Gómez J, et al. Predicting the result of noninvasive ventilation in severe acute exacerbations of patients with chronic airflow limitation. Chest. 2000;117:828-833.

30. Evans TW. International Consensus Conferences in Intensive Care Medicine: non-invasive positive-pressure ventilation in acute respiratory failure. Organised jointly by the American Thoracic Society, the European Respiratory Society, the European Society of Intensive Care Medicine, and the Société de Réanimation de Langue Française, and approved by the ATS Board of Directors, Dec 2000. Intensive Care Med. 2001;27:166-178.

31. British Thoracic Society Standards of Care Committee. Non-invasive ventilation in acute respiratory failure. Thorax. 2002;57:192-211.

32. Organized jointly by the American Thoracic Society, the European Respiratory Society, the European Society of Intensive Care Medicine, and the Société de Réanimation de Langue Française, and approved by ATS Board of Directors, December 2000. International Consensus Conferences in Intensive Care Medicine: noninvasive positive pressure ventilation in acute respiratory failure. Am J Respir Crit Care Med. 2001;163:283-291.

33. Barbé F, Togores B, Rubi M, Pons S, Maimó A, Agustí AG. Noninvasive ventilatory support does not facilitate recovery from acute respiratory failure in chronic obstructive pulmonary disease. Eur Respir J. 1996;9:1240-1245.

34. Keenan SP, Powers CE, McCormack DG. Noninvasive positivepressure ventilation in patients with milder chronic obstructive pulmonary disease exacerbations: a randomized controlled trial. Respir Care. 2005;50:610-616.

35. Nava S, Navalesi P, Conti G. Time of non-invasive ventilation. Intensive Care Med. 2006;32:361-370.

36. Squadrone E, Frigerio P, Fogliati C, et al. Noninvasive vs invasive ventilation in COPD patients with severe acute respiratory failure deemed to require ventilatory assistance. Intensive Care Med. 2004;30:1303-1310.

37. Schettino G, Altobelli N, Kacmarek RM. Noninvasive positivepressure ventilation in acute respiratory failure outside clinical trials: Experience at the Massachusetts General Hospital. Crit Care Med. 2008;36:441-447.

38. Demoule A, Girou E, Richard JC, Taillé S, Brochard L. Increased use of noninvasive ventilation in French intensive care units. Intensive Care Med. 2006;32:1747-1755.

39. Dwarakanath A, Elliott MW. Noninvasive ventilation in the management of acute hypercapnic respiratory failure. Breathe. 2013;9(5): $338-348$.

40. Chung LP, Winship P, Phung S, Lake F, Waterer G. Five-year outcome in COPD patients after their first episode of acute exacerbation treated with non-invasive ventilation. Respirology. 2010;15:1084-1091.

41. Vitacca M, Clini E, Rubini F, Nava S, Foglio K, Ambrosino N. Non-invasive mechanical ventilation in severe chronic obstructive lung disease and acute respiratory failure: short- and long-term prognosis. Intensive Care Med. 1996;22:94-100.
42. Titlestad L, Lassen AT, Vestbo J. Long-term survival for COPD patients receiving noninvasive ventilation for acute respiratory failure. Int $J$ Chron Obstruct Pulmon Dis. 2013;8:215-219.

43. Windisch W. Noninvasive positive pressure ventilation in COPD. Breathe. 2011;8:114-123.

44. Antón A, Güell R. Home mechanical ventilation in COPD: do we know when and how to use it? Chest. 2000;118(6):1525-1526.

45. Esquinas AM, Siscaro G, Clini EM. Noninvasive mechanical ventilation with high pressure strategy remains a "double edged sword"? Int J Chron Obstruct Pulmon Dis. 2013;8:255-256.

46. Struik FM, Lacasse Y, Goldstein RS, Kerstjens HA, Wijkstra PJ. Nocturnal nonninvasive positive pressure ventilation in stable COPD: A systematic review and individual patient data meta-analysis. Respiratory Medicine. 2014; 108:329-337.

47. Budweiser S, Hitzl AP, Jörres A, et al. Impact of noninvasive home ventilation on long-term survival in chronic hypercapnic COPD: a prospective observational study. Int J Clin Pract. 2007;61: 1516-1522.

48. Casanova C, Celli BR, Tost L, et al. Long-term controlled trial of nocturnal nasal positive pressure ventilation in patients with severe COPD. Chest. 2000;118(6):1582-1590.

49. Murphy PB, Brignall K, Moxham J, Polkey MI, Davidson AC, Hart N. High pressure versus high intensity noninvasive ventilation in stable hypercapnic chronic obstructive pulmonary disease: a randomized crossover trial. Int J Chron Obstruct Pulmon Dis. 2012;7:811-818.

50. Funk GC, Breyer MK, Burghuber OC, et al. Long-term non-invasive ventilation in COPD after acute-on-chronic respiratory failure. Respir Med. 2011;105:427-434.

51. Lukácsovits J, Carlucci A, Hill N, et al. Physiological changes during low- and high-intensity noninvasive ventilation. Eur Respir J. 2012;39:869-875.

52. Masip J, Planas K. Noninvasive ventilation. In: Tubaro M, Danchin N, Filippatos G, Goldstein P, Vranckx P, Zahger D, editors. The ESC Textbook of Intensive and Acute Cardiac Care. Oxford: Oxford University Press; 2011:215-226.

53. Lin M, Yang YF, Chiang HT, Chang MS, Chiang BN, Cheitlin MD. Reappraisal of continuous positive airway pressure therapy in acute cardiogenic pulmonary edema. Short-term results and long-term follow-up. Chest. 1995;107:1379-1386.

54. Kelly CA, Newby DE, McDonagh TA, et al. Randomised controlled trial of continuous positive airway pressure and standard oxygen therapy in acute pulmonary oedema; effects on plasma brain natriuretic peptide concentrations. Eur Heart J. 2002;23:1379-1386.

55. Moritz F, Benichou J, Vanheste M, et al. Boussignac continuous positive airway pressure device in emergency care of acute cardiogenic pulmonary oedema: a randomized pilot study. Eur J Emerg Med. 2003;10:204-208.

56. Crane SD, Elliott MW, Gilligan P, Richards K, Gray AJ. Randomised controlled comparison of continuous positive airways pressure, bilevel noninvasive ventilation, and standard treatment in emergency department in patients with acute cardiogenic oedema. Emerg Med J. 2004;21:155-161.

57. Räsänen J, Heikklä J, Downs J, Nikki P, Väisänen I, Viitanen A. Continuous positive airway pressure by face mask in acute cardiogenic pulmonary edema. Am J Cardiol. 1985;55:296-300.

58. Bersten AD, Holt AW, Vedig AE, Skowronski GA, Baggoley CJ. Treatment of severe cardiogenic pulmonary edema with continuous positive airway pressure delivered by face mask. $N$ Engl $J$ Med. 1991;325:1825-1830.

59. Takeda S, Nejima J, Takano T, et al. Effect of nasal continuous positive airway pressure on pulmonary edema complicating acute myocardial infarction. Jpn Circ J. 1998;62:553-558.

60. L'Her E, Duquesne F, Girou E, et al. Noninvasive continuous positive airway pressure in elderly cardiogenic pulmonary edema patients. Intensive Care Med. 2004;30:882-888.

61. Park M, Sangean MC, Volpe Mde S, et al. Randomized, prospective trial of oxygen, continuous positive airway pressure, and bilevel positive airway pressure by face mask in acute cardiogenic pulmonary edema. Crit Care Med. 2004;32:2407-2415. 
62. Masip J, Betbesé AJ, Páez J, et al. Non-invasive pressure support ventilation versus conventional oxygen therapy in acute cardiogenic pulmonary oedema: a randomised trial. Lancet. 2000;356: 2126-2132.

63. Levitt MA. A prospective, randomized trial of BiPAP in severe acute congestive heart failure. J Emerg Med. 2001;21:363-369.

64. Nava S, Carbone G, DiBattista N, et al. Noninvasive ventilation in cardiogenic pulmonary edema: a multicenter randomized trial. Am J Respir Crit Care Med. 2003;168:1432-1437.

65. Mehta S, Jay GD, Woolard RH, et al. Randomized, prospective trial of bilevel versus continuous positive airway pressure in acute pulmonary edema. Crit Care Med. 1997;25:620-628.

66. Moritz F, Brousse B, Gellée B, et al. Continuous positive airway pressure versus bilevel noninvasive ventilation in acute cardiogenic pulmonary edema: a randomized multicenter trial. Ann Emerg Med. 2007;50:666-675.

67. Liesching T, Nelson D, Cormier KL, et al. Randomized Trial of Bilevel versus Continuous Positive Airway Pressure for Acute Pulmonary Edema. J Emerg Med. 2014;46 (1):130-140.

68. Bellone A, Monani A, Cortellaro F, Vettorello M, Arlati S, Coen D. Myocardial infarction rate in acute pulmonary edema: noninvasive pressure support ventilation versus continuous positive airway pressure. Crit Care Med. 2004;32:1860-1865.

69. Bellone A, Vettorello M, Monari A, Cortellaro F, Coen D. Noninvasive pressure support ventilation vs continuous positive airway pressure in acute hypercapnic pulmonary edema. Intensive Care Med. 2005;31:807-811.

70. Rusterholtz T, Bollaert PE, Feissel M, et al. Continuous positive airway pressure vs proportional assist ventilation for noninvasive ventilation in acute cardiogenic pulmonary edema. Intensive Care Med. 2008;34:840-846.

71. Ho KM, Wong K. A comparison of continuous and bi-level positive airway pressure non-invasive ventilation in patients with acute cardiogenic pulmonary oedema: a meta-analysis. Crit Care. 2006;10:R49.

72. Nouira S, Boukef R, Bouida W, et al. Non-invasive pressure support ventilation and CPAP in cardiogenic pulmonary edema: a multicenter randomized study in the emergency department. Intensive Care Med. 2011;37:249-256.

73. Peter JV, Moran JL, Phillips-Hughes J, Graham P, Bersten AD. Effect of non-invasive positive pressure ventilation (NIPPV) on mortality in patients with acute cardiogenic pulmonary oedema: a meta-analysis. Lancet. 2006;367:1155-1163.

74. Winck J, Azevedo LF, Costa-Pereira A, Antonelli M, Wyatt JC. Efficacy and safety of non-invasive ventilation in the treatment of acute cardiogenic pulmonary edema: a systematic review and meta-analysis. Crit Care. 2006;10:R69.

75. Collins SP, Mielniczuk LM, Whittingham HA, Boseley ME, Schramm DR, Storrow AB. The use of noninvasive ventilation in emergency department patients with acute cardiogenic pulmonary edema: a systematic review. Ann Emerg Med. 2006;48:260-269.

76. Weng CL, Zhao YT, Liu QH, et al. Meta-analysis: noninvasive ventilation in acute cardiogenic pulmonary edema. Ann Intern Med. 2010;152:590-600.

77. Vital FMR, Saconato H, Ladeira MT, et al. Non-invasive positive pressure ventilation (CPAP or bilevel NPPV) for cardiogenic pulmonary edema (review). Cochrane Database of Systematic Reviews 2008, Issue 3. Art. No:CD005351.

78. Gray A, Goodacre S, Newby DE, Masson M, Sampson F, Nicholl J; 3CPO Trialists. Noninvasive ventilation in acute cardiogenic pulmonary edema. N Engl J Med. 2008;359:142-151.

79. Meduri GU, Cook TR, Turner RE, Cohen M, Leeper KV. Noninvasive positive pressure ventilation in status asthmaticus. Chest. 1996;110: 767-774.

80. Medoff BD. Invasive and noninvasive ventilation in patients with asthma. Respiratory care. 2008;53:740-748

81. Fernandez MM, Villagra A, Blanch L, Fernandez R. Non-invasive ventilation in status asthmaticus. Intensive Care Med. 2001;27:486-492.
82. Soroksky A, Stav D, Shpirer I. A pilot prospective, randomized, placebo-controlled trial of bilevel positive airway pressure in acute asthmatic attack. Chest. 2003;123:1018-1025.

83. Gupta D, Nath A, Agarwal R, Behera D. A prospective randomized controlled trial on the efficacy of noninvasive ventilation in severe acute asthma. Respir Care. 2010;55:536-543.

84. Lim WJ, Akram MR, Carson KV, et al Non-invasive positive pressure ventilation for treatment of respiratory failure due to severe acute exacerbations of asthma. Cochrane Database of Systematic Reviews 2012, Issue 12. Art. No: CD004360.

85. Wenzel S. Severe asthma in adults. Am J Respir Crit Care Med. 2005;172:149-160.

86. Lazarus SC. Emergency treatment of asthma. N Engl J Med. 2010;363: 755-764

87. Honrubia T, García López FJ, Franco N, et al. Noninvasive vs conventional mechanical ventilation for acute respiratory failure: a multicenter, randomized controlled trial. Chest. 2005;128: 3916-3924.

88. Jolliet P, Abajo B, Pasquina P, Chevrolet JC. Non-invasive pressure support ventilation in severe community-acquired pneumonia. Intensive Care Med. 2001;27:812-821.

89. Confalonieri M, Potena A, Carbone G, Porta RD, Tolley EA, Umberto Meduri G. Acute respiratory failure in patients with severe community-acquired pneumonia. A prospective randomized evaluation of noninvasive ventilation. Am J Respir Crit Care Med. 1999;160 1585-1591.

90. Ferrer M, Esquinas A, León M, González G, Alarcon A, Torres A. Noninvasive ventilation in severe hypoxemic respiratory failure: a randomized clinical trial. Am J Respir Crit Care Med. 2003;168: $1438-1444$.

91. Ferrer M, Esquinas A, Arancibia F, et al. Noninvasive ventilation during persistent weaning failure. A randomized controlled trial. Am J Respir Crit Care Med. 2003;168:70-76.

92. Jiang JS, Kao SJ, Wang SN. Effect of early application of biphasic positive airway pressure on the outcome of extubation in ventilator weaning. Respirology. 1999;4:161-165.

93. Nava S, Gregoretti C, Fanfulla F, et al. Noninvasive ventilation to prevent respiratory failure after extubation in high-risk patients. Crit Care Med. 2005;33:2465-2470.

94. Ferrer M, Valencia M, Nicolas JM, Bernadich O, Badia JR, Torres A. Early noninvasive ventilation averts extubation failure in patients at risk. Am J Respir Crit Care Med. 2006;173:164-170.

95. Ferrer M, Sellarés J, Valencia M, et al. Non-invasive ventilation after extubation in hypercapnic patients with chronic respiratory disorders: randomised controlled trial. Lancet. 2009;374:1082-1088.

96. Burns KE, Adhikari NK, Keenan SP, Meade M. Use of non-invasive ventilation to wean critically ill adults off invasive ventilation: meta-analysis and systemic review. BMJ. 2009;338:b1574.

97. Burns KEA, Meade MO, Premji A, Adhikari NKJ. Noninvasive positivepressure ventilation as a weaning strategy for intubated adults with respiratory failure. Cochrane Database of Systematic Reviews 2013, Issue 12. Art. No: CD004127. DOI: 10.1002/14651858.CD004127.pub3.

98. Girault C, Bubenheim M, Abroug F, et al; VENISE Trial Group. Noninvasive ventilation and weaning in patients with chronic hypercapnic respiratory failure patients: a randomized multicenter trial. Am J Respir Crit Care Med. 2011;184:672-679.

99. Vaschetto R, Turucz E, Dellapiazza F, et al. Noninvasive ventilation after early extubation in patients recovering from hypoxemic acute respiratory failure: a single-centre feasibility study. Intensive Care Med. 2012;38:1599-1606.

100. Zhu F, Liu ZL, Long X, et al. Effect of noninvasive positive pressure ventilation on weaning success in patients receiving invasive mechanical ventilation: a meta-analysis. Chin Med J (Engl). 2013;126(7): 1337-1343.

101. Su CL, Chiang LL, Yang SH, et al. Preventive use of noninvasive ventilation after extubation: a prospective, multicenter randomized controlled trial. Respir Care. 2012;57:204-210. 
102. Ornico SR, Lobo SM, Sanches HS, et al. Noninvasive ventilation immediately after extubation improves weaning outcome after acute respiratory failure: a randomized controlled trial. Crit Care. 2013; 17:R39.

103. Keenan SP, Powers C, McCormack DG, Block G. Noninvasive positive-pressure ventilation for postextubation respiratory distress: a randomized controlled trial. JAMA. 2002;287:3238-3244.

104. Esteban A, Frutos-Vivar F, Ferguson ND, et al. Noninvasive positive-pressure ventilation for respiratory failure after extubation. N Engl J Med. 2004;350:2452-2460.

105. Keenan SP, Sinuff T, Burns K, et al; Canadian Critical Care Trials Group/Canadian Critical Care Society Noninvasive Ventilation Guidelines Group. Clinical practice guidelines for the use of noninvasive positive-pressure ventilation and noninvasive continuous positive airway pressure in the acute care setting. CMAJ. 2011;183(3): E195-E214.

106. Agarwal R, Reddy C, Aggarwal AN, Gupta D. Is there a role for noninvasive ventilation in acute respiratory distress syndrome? A meta-analysis. Respir Med. 1006;100:2235-2238.

107. Rana S, Jenad H, Gay PC, Buck CF, Hubmayr RD, Gajic O. Failure of non-invasive ventilation in patients with acute lung injury: Observational cohort study. Crit Care. 2006;10:R79.

108. Delclaux C, L'Her E, Alberti C, et al. Treatment of acute hypoxemic nonhypercapnic respiratory insufficiency with continuous positive airway pressure delivered by a face mask: a randomized controlled trial. JAMA. 2000;284:2352-2360.

109. Antonelli M, Conti G, Esquinas A, et al. A multiple-center survey on the use in clinical practice of noninvasive ventilation as a first-line intervention for acute respiratory distress syndrome. Crit Care Med. 2007;35:18-25.

110. Hilbert G, Gruson D, Vargas F, et al. Noninvasive ventilation in immunocompromised patients with pulmonary infiltrates, fever, and acute respiratory failure. $N$ Engl J Med. 2001;344:481-487.

111. Antonelli M, Conti G, Bufi M, et al. Noninvasive ventilation for treatment of acute respiratory failure in patients undergoing solid organ transplantation: a randomized trial. JAMA. 2000;283:235-241.

112. Depuydt PO, Benoit DD, Vandewoude KH, Decruyenaere JM, Colardyn FA. Outcome in noninvasively and invasively ventilated hematologic patients with acute respiratory failure. Chest. 2004;126: 1299-1306.

113. Belenguer-Muncharaz A, Albert-Rodrigo L, Ferrandiz-Sellés A, Cebrián-Graullera G. Evolución de 10 años de aplicación de la ventilación mecánica en la insuficiencia respiratoria aguda del paciente hematológico ingresado en la unidad de cuidados intensivos. Med Intensiva. 2013;37:452-460.

114. Gristina GR, Antonelli M, Conti G, et al; GiViTI (Italian Group for the Evaluation of Interventions in Intensive Care Medicine). Noninvasive versus invasive ventilation for acute respiratory failure in patients with hematologic malignancies: a 5-year multicenter observational survey. Crit Care Med. 2011;39(10):2232-2239.

115. Depuydt PO, Benoit DD, Roosens CD, Offner FC, Noens LA, Decruyenaere JM. The impact of the initial ventilatory strategy on survival inhematological patients with acute hypoxemic respiratory failure. J Crit Care. 2010;25:30-36.

116. Barbas CSV, Couto LP, Kawano-Dourado LB. Noninvasive ventilation for acute respiratory failure in patients with hematologic malignancies: what an Italian 5-year multicenter survey tells us. Crit Care Med. 2011;39(10):2358-2359.

117. Kingden-Milles D, Müller E, Buhl R, et al. Nasal-continuous positive airway pressure reduces pulmonary morbidity and length of hospital stay following thoracoabdominal aortic surgery. Chest. 2005;128: 821-828.

118. Altmay E, Karaca P, Yurtseven N, et al. Continuous positive airway pressure does not improve lung function after cardiac surgery. Can J Anaesth. 2006;53:919-925.

119. Gaszynski T, Tokarz A, Piotrowski D, Machala W. Boussignac CPAP in the postoperative period in morbidly obese patients. Obes Surg. 2007; 17:452-456.
120. Auriant I, Jallot A, Hervé P, et al. Noninvasive ventilation reduces mortality in acute respiratory failure following lung resection. $\mathrm{Am} \mathrm{J}$ Respir Crit Care Med. 2001;164:1231-1235.

121. Squadrone V, Coha M, Cerruti E, et al; Piedmont Intensive Care Units Network (PICUN). Continuous positive airway pressure for treatment of postoperative hypoxemia. a randomized controlled trial. JAMA. 2005;293:589-595.

122. Azoulay E, Demoule A, Jaber A, et al. Palliative noninvasive ventilation in patients with acute respiratory failure. Intensive Care Med. 2011;37:1250-1257.

123. Levy M, Tanios MA, Nelson D, et al. Outcomes of patients with donot-intubate orders treated with noninvasive ventilation. Crit Care Med. 2004;32:2002-2007.

124. Nava S, Ferrer M, Esquinas A, et al. Palliative use of non-invasive ventilation in end-of-life patients with solid tumors: a randomised feasibility trial. Lancet Oncol. 2013;14:219-217.

125. Devlin JW, Nava S, Fong JJ, Bahhady I, Hill NH. Survey of sedation practices during noninvasive positive-pressure ventilation to treat acute respiratory failure. Crit Care Med. 2007;35:2298-2302.

126. Chiumello D, Coppola S, Froio S, Gregoretti C, Consonni D. Noninvasive ventilation in chest trauma: systematic review and meta-analysis. Intensive Care Med. 2013;39:1171-1180.

127. Shneerson JM, Simonds K. Noninvasive ventilation for chest wall and neuromuscular disorders. Eur Respir J. 2002;20:480-487.

128. Hill N, Garpestad E, Brennan J. Response [letter]. Chest. 2008;133(1):314-315.

129. Murgu SD, Pecson J, Colt H. Bronchoscopy during noninvasive ventilation: indications and technique. Respir Care. 2010;55(5): 595-600.

130. Contal O, Adler D, Borel JC, et al. Impact of different backup respiratory rates on the efficacy of noninvasive positive pressure ventilation in obesity hypoventilation syndrome: a randomized trial. Chest. 2013;143(1):37-46.

131. Janssens JP, Metzger M, Sforza E. Impact of volume targeting on efficacy of bi-level non-invasive ventilation and sleep in obesityhypoventilation. Respir Med. 2009;103:165-172.

132. Bakker JP, Marshall NS. Flexible pressure delivery modification of continuous positive airway pressure for obstructive sleep apnea does not improve compliance with therapy: systematic review and meta-analysis. Chest. 2011;139:1322-1330.

133. Carrillo A, Ferrer M, Gonzalez-Diaz G, et al. Noninvasive ventilation in acute hypercapnic respiratory failure caused by obesity hypoventilation syndrome and chronic obstructive pulmonary disease. Am J Respir Crit Care Med. 2012;186:1279-1285.

134. Kasai T, Usui Y, Yoshioka T, et al; JASV Investigators. Effect of flowtriggered adaptive servo-ventilation compared with continuous positive airway pressure in patients with chronic heart failure with coexisting obstructive sleep apnea and Cheyne-stokes Respiration. Circ Heart Fail. 2010;3:140-148.

135. Carlucci A, Richard JC, Wysocki M, Lepage E, Brochard L; SRLF Collaborative Group on Mechanical Ventilation. Noninvasive versus conventional mechanical ventilation. An epidemiologic survey. Am J Respir Crit Care Med. 2001;163:874-880.

136. Garpestad E, Brennan J, Hill NS. Noninvasive ventilation for critical care. Chest. 2007;132:711-720.

137. Lellouche F, Brochard L. Advanced closed loops during mechanical ventilation (PAV, NAVA, ASV, SmartCare). Best Pract Res Clin Anaesthesiol. 2009;23:81-93.

138. Fernández-Vivas M, Caturla-Such J, González de la Rosa J, Acosta-Escribano J, Alvarez-Sánchez B, Cánovas-Robles J. Noninvasive pressure support versus proportional assist ventilation in acute respiratory failure. Intensive Care Med. 2003;29:1126-1133.

139. Gay PC, Hess DR, Hill NS. Noninvasive proportional assist ventilation for acute respiratory insufficiency: comparison with pressure support ventilation. Am J Respir Crit Care Med. 2001;164: 1606-1611. 
140. Wysocki M, Richard JC, Meshaka P. Noninvasive proportional assist ventilation compared with noninvasive pressure support ventilation in hypercapnic acute respiratory failure. Crit Care Med. 2002;30:323-329.

141. Lee JH, Rehder KJ, Williford L, Cheifetz IM, Turner DA. Use of high flow nasal cannula in critically ill infants, children, and adults: a critical review of the literature. Intensive Care Med. 2013;39:247-257.

142. Piquilloud L, Tassaux D, Bialais E, et al. Neurally adjusted ventilatory assist (NAVA) improves patient-ventilator interaction during noninvasive ventilation delivered by face mask. Intensive Care Med. 2012;38:1624-1631.

143. Gama de Abreu M, Belda FJ. Neurally adjusted ventilatory assist: letting the respiratory center take over control of ventilation. Intensive Care Med. 2013;39:1481-1483.

144. Bertrand PM, Futier E, Cosiel Y, Metecki S, Jaber S, Constantin JM. Neurally adjusted ventilatory assist vs pressure support ventilation for noninvasive ventilation during acute respiratory failure. Chest. 2013;143:30-36.

145. Mireles-Cabodevila E, Chatburn RL. Work of breathing in adaptive pressure control continuous mandatory ventilation. Respir Care. 2009;54:1467-1472.

146. Briones Claudett KH, Briones Claudett M, Chung Sang Wong M, et al. Noninvasive mechanical ventilation with average volume assured pressure support (AVAPS) in patients with chronic obstructive pulmonary disease and hypercapnic encephalopathy. BMC Pulm Med. 2013;13:12.

147. Dellweg D, Kerl J, Hoehn E, Wenzel M, Koehler D. Randomized controlled trial of noninvasive positive pressure ventilation (NPPV) versus servoventilation in patients with CPAP-induced central sleep apnea (complex sleep apnea). Sleep. 2013;36(8):1163-1171.

148. Sharma BK, Bakker JP, McSharry DG, Desai AS, Javaheri S, Malhotra A. Adaptive servoventilation for treatment of sleep-disordered breathing in heart failure: a systematic review and meta-analysis. Chest 2012;142(5):1211-1221.

149. Fodil R, Lellouche F, Mancebo J. Comparison of patient-ventilator interfaces based on their computerized effective dead space. Intensive Care Med. 2011;37:257-262.

150. Pravinkumar SE. A face that matters in distress: interface selection for acute noninvasive ventilation. Crit Care Med. 2009;37:344-345.

151. Navalesi P, Fanfulla F, Frigerio P, Gregoretti C, Nava S. Physiologic evaluation of noninvasive mechanical ventilation delivered with three types of masks in patients with chronic hypercapnic respiratory failure. Crit Care Med. 2000;28:1785-1790.

152. Willing S, San Pedro M, Driver HS, Munt P, Fitzpatrick MF. The acute impact of continuous positive airway pressure on nasal resistance: a randomized controlled comparison. J Appl Physiol. 2007;102: 1214-1219.

153. Girault C, Briel A, Benichou J, et al. Interface strategy during noninvasive positive pressure ventilation for hypercapnic acute respiratory failure. Crit Care Med. 2009;37:124-131.

154. Crimi C, Noto A, Princi P, Esquinas A, Nava S. A European survey of noninvasive ventilation practices. Eur Respir J. 2010;36:362-369.

155. Kwok H, McCormack J, Cece R, Houtchens J, Hill NS. Controlled trial of oronasal versus nasal mask ventilation in the treatment of acute respiratory failure. Crit Care Med. 2003;31:468-473.

156. Gerard J, Criner G, Travalina J, Brennan K, Kreimer D. Efficacy of a new full face mask for non-invasive positive pressure ventilation. Chest. 1994;106:1109-1115.

157. Chacur FH, Vilella Felipe LM, Fernandes CG, Lazzarini LC. The total face mask is more comfortable than the oronasal mask in noninvasive ventilation but is not associated with improved outcome. Respiration. 2011;82:426-430.

158. Lemyze M, Mallat J, Nigeon $\mathrm{O}$, et al. Rescue therapy by switching to total face mask after failure of face mask-delivered noninvasive ventilation in do-not-intubate patients in acute respiratory failure. Crit Care Med. 2013;41:481-488.

159. Ozsancak A, Sidhom SS, Liesching TN, Howard W, Hill NS Evaluation of the total face mask for noninvasive ventilation to treat acute respiratory failure. Chest. 2011;139:1034-1041.
160. Cavaliere F, Conti G, Costa R, Proietti R, Sciuto A, Masieri S. Noise exposure during noninvasive ventilation with a helmet, a nasal mask and a facial mask. Intensive Care Med. 2004;30:1755-1760.

161. Navalesi P, Costa R, Ceriana P, et al. Non-invasive ventilation in chronic obstructive pulmonary disease patients: helmet versus facial mask. Intensive Care Med. 2007;33:74-81.

162. Vargas F, Thille A, Lyazidi A, Campo FR, Brochard L. Helmet with specific settings versus facemask for noninvasive ventilation. Crit Care Med. 2009;37:1921-1928.

163. Schneider E, Dualé C, Vaille JL, et al. Comparison of tolerance of facemask vs mouthpiece for non-invasive ventilation. Anaesthesia. 2006;61:20-23.

164. Fraticelli AT, Lellouche F, L'Her E, Taillé S, Mancebo J, Brochard L. Physiological effects of different interfaces during noninvasive ventilation for acute respiratory failure. Crit Care Med. 2009;37:939-945.

165. Carteaux G, Lyazidi A, Cordoba-Izquierdo A, et al. Patient-ventilator asynchrony during noninvasive ventilation: a bench and clinical study. Chest. 2012;142(2):367-376.

166. Nava S, Ambrosino N, Bruschi C, Confaleroni M, Rampolla C. Physiological effects of flow and pressure triggering during non-invasive mechanical ventilation in patients. Thorax. 1997;52:249-254.

167. Bellani G, Guiseppe F, Spagnolli E, Castagna L, Patroniti N, Pesenti A. An improved Boussignac device for the delivery of non-invasive CPAP: the SUPER-Boussignac. Intensive Care Med. 2009;35: 1094-1099.

168. American Association for Respiratory Care, Restrepo R, Walsh BK. Humidification during invasive and noninvasivemechanical ventilation; 2012. Respir Care. 2012;57(5):782-788.

169. Oto J, Imanaka H, Nishimura M. Clinical factors affecting inspired gas humidification and oral dryness during noninvasive ventilation. $J$ Crit Care. 2011;26:535.e9-535.e15.

170. Hess DR. The evidence for noninvasive positive-pressure ventilation in the care of patients in acute respiratory failure: a systematic review of the literature. Respir Care. 2004;48:810-829.

171. Liesching T, Kwok H, Hill NS. Acute applications of noninvasive positive pressure ventilation. Chest. 2003;124:669-713.

172. Lellouche M, Maggiore SM, Deye N, et al. Effect of the humidification device on the work of breathing during noninvasive ventilation. Intensive Care Med. 2002;28:1582-1589.

173. Jaber S, Chanques G, Matecki S, et al. Comparison of the effects of heat and moisture exchangers and heat humidification on ventilation and gas exchange during non-invasive ventilation. Intensive Care Med. 2002;28:1590-1594.

174. Hubble MW, Richards ME, Jarvis R, Millikan T, Young D. Effectiveness of prehospital continuous positive airway pressure in the management of acute pulmonary edema. Prehosp Emerg Care. 2006; 10:430-439.

175. Ducros L, Logeart D, Vicaut E, et al; CPAP collaborative study group. CPAP for acute cardiogenic pulmonary oedema from out-of-hospital to cardiac intensive care unit : a randomised multicentre study. Intensive Care Med. 2011;37:1501-1509.

176. Mas A, Alonso G, Perez C, Saura P, Alcoverro JM, Guirado M. Non-invasive mechanical ventilation for acute dyspnea in out-of-hospital emergency care [abstract]. Intensive Care Med. 2002;28:256,S69.

177. Roessler MS, Schmid D, Michels P, et al. Early out-of-hospital non-invasive ventilation is superior to standard medical treatment in patients with acute respiratory failure: a pilot study. Emerg Med J. 2012;29(5):409-414.

178. Esteban A, Ferguson ND, Meade MO, et al; VENTILA Group. Evolution of mechanical ventilation in response to clinical research. Am J Respir Crit Care Med. 2008;177:170-177.

179. Sinuff T, Cook D, Randall J, Allen C. Noninvasive positive-pressure ventilation: a utilization review of use in a teaching hospital. CMAJ. 2000;163:969-973.

180. Hess DR. Noninvasive ventilation for acute respiratory failure. Respir Care. 2013;58:950-972. 
181. Soo Hoo GW, Santiago S, Williams AJ. Nasal mechanical ventilation for hypercapnic respiratory failure in chronic obstructive pulmonary disease: determinants of success and failure. Crit Care Med. 1994;22:1253-1261.

182. Poponick JM, Renston JP, Bennett RP, Emerman CL. Use of a ventilatory support system (BiPAP) for acute respiratory failure in the emergency department. Chest. 1999;116:166-171.

183. Schettino G, Altobelli N, Kacmarek R. Noninvasive positive-pressure ventilation in acute respiratory failure outside clinical trials: experience at the Massachusetts General Hospital. Crit Care Med. 2008;36:441-447.

184. Elliott MW. The interface: crucial for successful noninvasive ventilation. Eur Respir J. 2004;23:7-8.

185. Di Marco F, Centanni S, Bellone A, et al. Optimization of ventilator setting by flow and pressure waveforms analysis during noninvasive ventilation for acute exacerbations of COPD: a multicentric randomized controlled trial. Crit Care. 2011;15:R283.
186. Vignaux L, Vargas F, Roeseler J, et al. Patient-ventilator asynchrony during non-invasive ventilation for acute respiratory failure: a multicenter study. Intensive Care Med. 2009;35:840-846.

187. Huang Z, Chen YS, Yang ZL, Liu JY. Dexmedetomidine versus midazolam for the sedation of patients with non-invasive ventilation failure. Intern Med. 2012;51:2299-2305.

188. Constantin JM, Schneider E, Cayot-Constantin S, et al. Remifentanilbased sedation to treat noninvasive ventilation failure: a preliminary study. Intensive Care Med. 2007;33:82-87.

189. Senoglu N, Oksuz H, Dogan Z, Yildiz H, Demirkiran H, Ekerbicer H. Sedation during noninvasive mechanical ventilation with dexmedetomidine or midazolam: a randomized, double-blind, prospective study. Curr Ther Res Clin Exp. 2010;71:141-153.

190. Duan J, Tang X, Huang S, Jia J, Guo S. Protocol-directed versus physician-directed weaning from noninvasive ventilation: the impact in chronic obstructive pulmonary disease patients. J Trauma Acute Care Surg. 2012;72:1271-1275.

\section{Publish your work in this journal}

The International Journal of COPD is an international, peer-reviewed journal of therapeutics and pharmacology focusing on concise rapid reporting of clinical studies and reviews in COPD. Special focus is given to the pathophysiological processes underlying the disease, intervention programs, patient focused education, and self management protocols.

\section{Dovepress}

This journal is indexed on PubMed Central, MedLine and CAS. The manuscript management system is completely online and includes a very quick and fair peer-review system, which is all easy to use. Visit http://www.dovepress.com/testimonials.php to read real quotes from published authors. 